\title{
Tail-vibrating Behavior in an Indian Egg-Eater (Boiga westermanni), Common Catsnake (Boiga trigonata), Banded Kukri (Oligodon arnensis), and Common Wolfsnake (Lycodon aulicus) from India
}

Rahul V. Deshmukh¹, Sagar A. Deshmukh², Swapnil A. Badhekar³, Shubham Katgube ${ }^{4}$, Swapnil Bhondawe ${ }^{5}$, and Ritik Shete ${ }^{6}$

1H.N. 26, Teacher Colony, Kalmeshwar, Nagpur, Maharashtra-441501, India (rahul30.sake@gmail.com)

${ }^{2}$ Behind Potdar Nursing Home, Kalmeshwar, Nagpur, Maharashtra-441501, India (sd.snakefriend@gmail.com)

${ }^{3}$ Tiwaskarwadi, Raipur, Hingana, Nagpur, Maharashtra-441110, India (swapnilbadhekar86@gmail.com)

${ }^{4}$ Saoner Ring Road, Kaleshwar, Brahmani, Nagpur, Maharashtra-441501, India (subham95.snake@gmail.com)

${ }^{5}$ Dhangarpura, Ward no. 3, Near Ahilyabai Temple, Hingana, Nagpur, Maharashtra-441110, India (swapnilbhondawe29@gmail.com)

${ }^{6}$ Ward no. 5, near Post Office, Ambhore Nagar, Raipur, Hingana, Nagpur, Maharashtra-441110, India (ritikshete2@gmail.com)

$\mathrm{T}$ ail-vibrating behavior might serve slightly different functions for different species. Greene (1973) listed three possible goals of tail-shaking, all of which are defensive: (1) diverting a predator to attack the tail, (2) confusing a predator, and (3) inhibiting an attack by advertising a venomous bite. Such defensive tail displays have been documented in the snakes of the families Aniliidae, Cylindrophiidae, Elapidae, Colubridae, and Dipsadidae (e.g., Greene 1973; Marques 2000). Mehta (2006) suggested that juveniles were more likely to vibrate their tails than adults and attributed that to an inability to escape due to limitations in size and development. However, such displays, even in adults, may be induced by conditions (e.g., recent feeding events, high stress levels, lower body temperatures, pregnancy or gravidity, or shedding) that limit opportunities for escape (e.g., Greene 1973; Mori and Burghardt 2004; Mehta 2006). Herein, we describe tail-vibrating behavior in four colubrids from India.

Indian Egg-Eater, Boiga westermanni (Reinhardt 1863).-At 2120 h on 14 September 2018, RVD, SAD, and SK rescued an adult male Indian Egg-Eater from the second floor of a residential building near the Indian Tiles Showroom in the MIDC Area Kalmeshwar-Brahmani, Nagpur, Maharashtra $\left(21.225847^{\circ} \mathrm{N}, 78.904314^{\circ} \mathrm{E}\right)$. During the rescue, the snake elevated and coiled the anterior part of its body into an S-shape and flattened its head and neck while rapidly vibrating its tail (Fig. 1; video available at http:// youtu.be/NaKbyXPZGY0). The snake vibrated its tail for 70 minutes while continuously attempting to strike, holding a striking position for $4-5$ minutes at a time before dropping its head to the ground but maintaining the S-shape in the anterior body. When attempts to escape were unsuccessful, it quickly reverted to its aggressive mode with tail vibrations. We subsequently released the snake into suitable habitat in the vicinity of where it was rescued.

Common Catsnake, Boiga trigonata (Schneider 1802).-At $2215 \mathrm{~h}$ on 16 August 2018, during a roadkill survey, RVD and SAB encountered a young Common Catsnake on a blacktop road between Kalmeshwar and Katol near Sri Bhagirath Textile Pvt. Ltd., Kohali, Kalmwshwar, Nagpur, Maharashtra $\left(21.253576^{\circ} \mathrm{N}, 78.822702^{\circ} \mathrm{E}\right)$. When

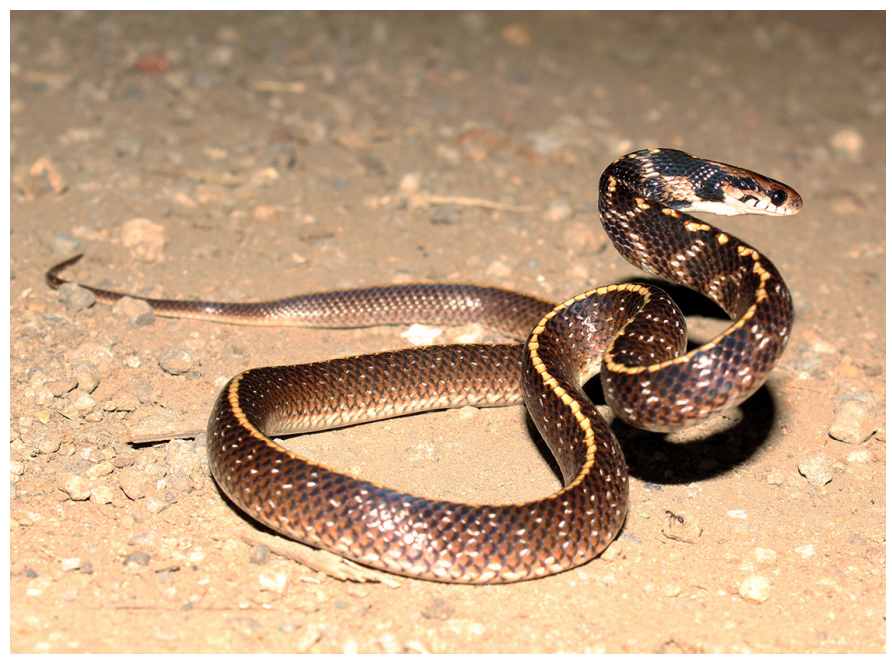

Fig. 1. An adult Indian Egg-Eater (Boiga westermanni) elevating and coiling the anterior part of its body into an S-shape while rapidly vibrating its tail. Photograph by Rahul V. Deshmukh. 


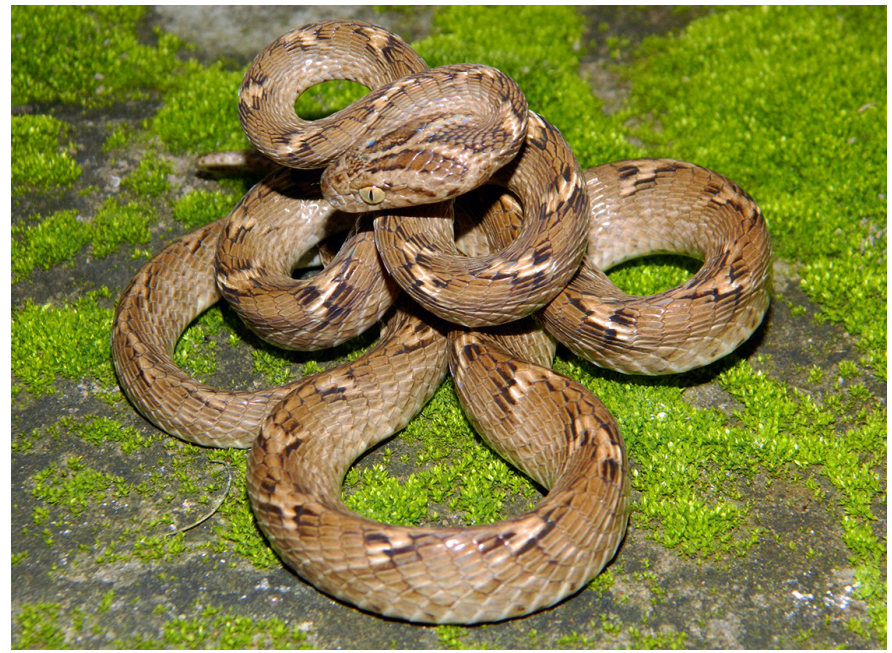

Fig. 2. When approached this young Common Catsnake (Boiga trigonata) assumed a striking position and started rapidly vibrating its tail. Photograph by Sagar A. Deshmukh.

approached, the snake elevated and formed the anterior portion of its body into an S-shape while rapidly vibrating its tail (Fig. 2; video available at http://youtu-be/ir5HmZp4NqE). It vibrated its tail for 22 minutes while continuously striking. We left the site twice but observed the snake from a distance. It maintained the same position for some time before slowly moving into the roadside vegetation.

Banded Kukri, Oligodon arnensis (Shaw 1802). - At 0705 h on 13 August 2019, SAB and SB rescued a young unsexed Banded Kukri at the Snehal Public School, Hingana, Nagpur, Maharashtra $\left(21.067940^{\circ} \mathrm{N}, 78.963388^{\circ} \mathrm{E}\right)$. We captured the snake and placed it in a transparent plastic jar, where it began vibrating its tail (Fig. 3; video available at http://youtu. be/jv6AnpXGC-Q). The snake was aggressive and continuously

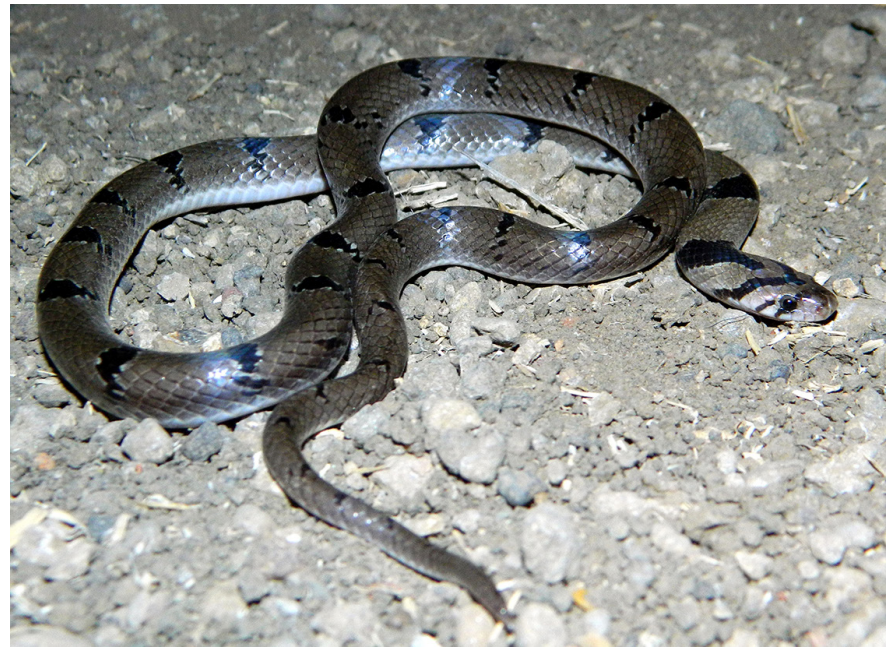

Fig. 3. While being released, this young Banded Kukri (Oligodon arnensis) exhibited tail-vibrating behavior. Photograph by Sagar A. Deshmukh.

vibrated its tail for 45 minutes. We subsequently released it into suitable habitat in a nearby forest in the city of Hingana.

At 1000 h on 23 August 2019, RS rescued an unsexed young Banded Kukri from Hanuman Nagar behind Sut Girani, Nagpur, Maharashtra $\left(21.130976^{\circ} \mathrm{N}, 79.003550^{\circ} \mathrm{E}\right)$. Although calm at the time of rescue and when initially placed in a transparent plastic jar, it began vibrating its tail when we released it at about $1130 \mathrm{~h}$ (video available at https:// youtu.be/3goZC0E3Uro). The snake elevated and formed an $\mathrm{S}$-shape with the anterior part of its body while vibrating its tail and striking continuously for approximately 35 minutes.

Common Wolfsnake, Lycodon aulicus (Linnaeus 1758).-We recorded 11 instances of tail-vibrating behavior in Common Wolfsnakes (Fig. 4; Table 1).

Table 1. Common Wolf Snakes (Lycodon aulicus) exhibiting tail-vibrating behavior.

\begin{tabular}{lllll} 
Location & Behavior & Movement & Apparent Function & Observer (year) \\
\hline Kalmeshwar & Striking \& tail vibration & Moving \& stationary & Escape \& threat & RVD (2013) \\
\hline Jalalkheda & Anterior S-shape \& tail vibration & Stationary & Threat & RVD (2013) \\
\hline Gorewada & Sideways striking \& tail vibration & Stationary & Threat & RVD (2013) \\
\hline Kalmeshwar & Head butting \& tail vibration & Active in place & Threat & SAD (2014) \\
\hline Kalmeshwar & Striking \& tail vibration & Moving & Escape & SAD (2015) \\
\hline Hingana & Striking \& tail vibration & Moving \& stationary & Escape \& threat & SAB (2015) \\
\hline Raipur, Hingana & Anterior S-shape \& tail vibration & Moving \& stationary & Escape \& threat & SAB $(2015)$ \\
\hline Vanadongari & Anterior S-shape \& tail vibration & Stationary & Threat & SAB (2016) \\
\hline Kalmesshwar & Sideways striking \& tail vibration & Stationary & Threat & SK (2017) \\
\hline Hingana & Anterior S-shape \& tail vibration & Moving & Escape & SB (2019) \\
\hline Umred & Striking \& tail vibration & Stationary & Threat & RVD (2019) \\
\hline
\end{tabular}




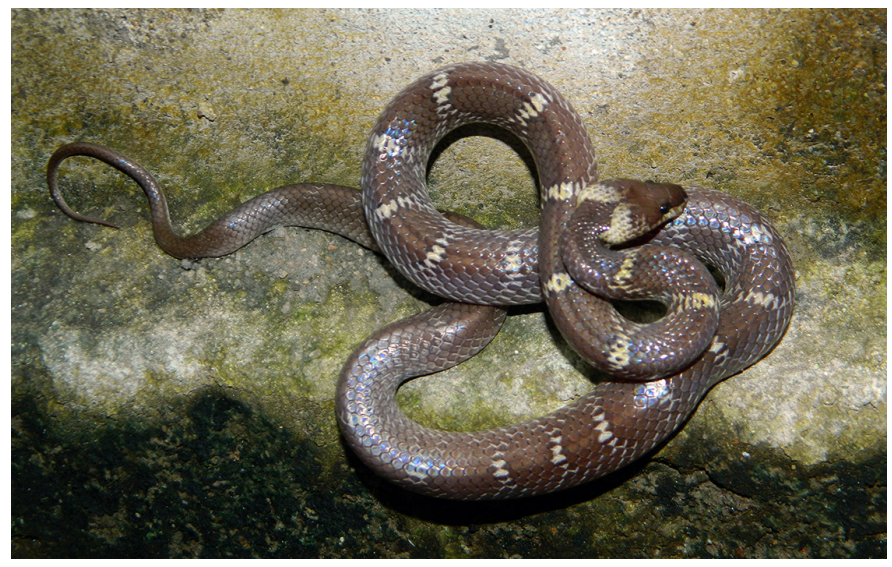

Fig. 4. An adult Common Wolfsnake (Lycodon aulicus) from Kalmeshwar, Maharashtra, vibrating its tail. Photograph by Rahul V. Deshmukh.

\section{Acknowledgements}

We are very grateful to Priyanshi Badhekar, Aniket Parbat, Krutik Bhachale, Sanjay Wasake, and Sagar Kanfade.

\section{Literature Cited}

Greene, H.W. 1973. Defensive tail display by snakes and amphisbaenians. Journal of Herpetology 7: 143-161.

Marques, O.A.V. 2000. Tail displays of the false coral snake Simophis rhinostoma (Colubridae). Amphibia-Reptilia 22: 127-129.

Mehta, R.S. 2006. Meal size effects on antipredator behavior of hatching trinket snakes, Elaphe helena. Ethology 116: 649-656.

Mori, A. and G.M. Burghardt. 2004. Thermal effects on the antipredator behaviour of snakes: a review and proposed terminology. Herpetological Journal 14: $79-87$. 